\title{
Some parasites that affect the skin in the human being: Epidemiological aspects
}

\begin{abstract}
Parasites that affect the skin in humans compromise health, but its epidemiological characterization is difficult due to the lack of official records. The purpose of this work was to describe some epidemiological characteristics of leishmaniasis, filariasis, echinococcosis, scabies and pediculosis as parasites that injure the skin. The present work was based on the documentary review of scientific literature in electronic format on the subject. It is concluded that there is no uniformity in the existing epidemiological studies on parasites that injure skin, and that this report provides information to the health agencies of the countries for the control of such a relevant public health problem.
\end{abstract}

Volume 2 Issue 6 - 2018

Gilberto A Bastidas Pacheco, Daniel Bastidas
Department of Public Health, University of Carabobo,Venezuela

Correspondence: Gilberto A Bastidas Pacheco, Doctor in Parasitology, Department of Public Health, University of Carabobo, San Diego, Carabobo state,Venezuela, Tel +5842 4778 9944, Email bastibasprotozoo@hotmail.com

Received: August 24, 2018 | Published: November 05, 2018

Keywords: parasites, skin, epidemiology, public health

\section{Introduction}

The parasites that affect the skin, in relation to any organism that lives and develops at the expense of another, from which they feed, to weaken it (the degree of evolution in adaptation is variable), that in some cases produces death, are fundamentally protozoan (leishmaniasis), helminths (filariasis and echinococcosis) and arthropods (scabies and pediculosis), are real public health problems given the important role of protection against external agents that makes the skin, because the damage is compromised the health and work performance of the affected, however, the epidemiological characterization of parasites that injure the skin is difficult, due to, among other factors, the lack of official records in many countries where these pathologies are endemic., ${ }^{1,2}$

From the above it is clear the importance or objective of this writing, to show, although in a concise way, information about the epidemiological behavior of cutaneous parasitism in the human being, reported by several authors in the world literature, specifically of leishmaniasis, filariasis, echinococcosis, scabies and pediculosis, in an effort to contribute with the updating of the findings, with the ultimate goal of contributing to the prevention and control of such a serious health problem, which produces severe economic damage in the first place to the countries and in second place the affected and his family, for the important and growing monetary investments that must be made in search of the cure.

\section{Methodology}

The present work was based on the documentary review of scientific literature in electronic format on some epidemiological aspects of parasites that affect human skin, for this we used virtual databases (Bireme/OPS, Medline, PudMed, Scielo) from descriptors or keywords related to constructs or proposals and name of authors. Likewise, repeated documents in the search engines were excluded, as well as those without clear conclusions and without originality.

\section{Epidemiological aspects of some parasites that affect human skin}

It is evident that there are two parasitism arthropod that most often infect humans, scabies and pediculosis, in this sense it is known that every year more than 300 million new cases of scabies (Sarcoptes scabiei) worldwide, with an epidemiological behavior characterized by affectation of all races, cyclical epidemic appearance under the condition of overcrowding and poverty, and more frequently in underdeveloped or developing countries. Regarding the pediculosis head, eyebrows and eyelashes, produced by Pediculus humanus capitis, and pubic hair caused by Phthirus pubis, unreliable, except epidemiological data found that like scabies is prevalent in overcrowding and poverty. ${ }^{1,3-5}$

For filariasis (Loa loa, Onchocerca volvulus, Dracunculus medinensis and Mansonella perstans) some 10 million people in the world are parasitized by transmission between humans through the female of an arthropod. Echinococcosis is considered a zoonosis which also affects humans (to act as intermediate host), produced by tapeworms of the genus Echinococcus, of the five species, Echinococcus granulosus is the one that everyone is present except Antarctica. However, rates of echinococcosis in humans range from 1 to 200 cases per 100,000 inhabitants in rural areas of developing countries. ${ }^{1,2,5}$

Finally, American tegumentary leishmaniasis has a worldwide distribution, with an annual incidence of 1 to 1.5 million cases, being described in 16 Asian countries, 22African and 21American. Approximately $95 \%$ of cases of tegumentary leishmaniasis occur in the Americas, the Mediterranean basin, the Middle East, and Central Asia. In Afghanistan, Algeria, Brazil, Colombia, the Islamic Republic of Iran and the Syrian Arab Republic, more than two thirds of new cases are recorded (between 0.6 and 1 million). ${ }^{5-7}$

\section{Conclusion}

As can be seen, there is no uniformity or equal depth in epidemiological studies with regard to parasites that injure skin, and this small report also provides information to health agencies in the countries to control such a relevant public health problem.

\section{Acknowledgements}

None. 


\section{Conflicts of interest}

The authors declare no conflicts of interest.

\section{References}

1. Allevato M. Infecciones parasitarias de la piel. Act Terap Dermatol. 2006;29:268-278.

2. de Argôlo E, Reis T, Fontes D, et al. Canine filariasis in the Amazon: Species diversity and epidemiology of these emergent and neglected zoonoses. PLoS One. 2018;11;13(7):e0200419.

3. Cassell J, Middleton J, Nalabanda A, et al. Scabies outbreaks in ten care homes for elderly people: a prospective study of clinical features, epidemiology, and treatment outcomes. Lancet Infect Dis. 2018;18(8):894-902.
4. Cetinkaya Ü, Sahin S, Ulutabanca R. The Epidemiology of Scabies and Pediculosis in Kayseri. Turkiye Parazitol Derg. 2018;42(2):134-137.

5. WHO. Leishmaniasis. 2017.

6. Scorza JV. Ecología Neo tropical de cuatro parasitosis humanas. Bol Soc Venez Ci Nat. 1980;34(137):206-266.

7. Silva J, Queiroz A, Moura I, et al. Dynamics of American tegumentary leishmaniasis in a highly endemic region for Leishmania (Viannia) braziliensis infection in northeast Brazil. PLoS Negl Trop Dis. 2017;11(11):e0006015. 